\title{
Changes of myocardial gene expression and protein composition in patients with dilated cardiomyopathy after immunoadsorption with subsequent immunoglobulin substitution
}

\author{
Sabine Ameling ${ }^{1,7} \cdot$ Gourav Bhardwaj $^{1,7} \cdot$ Elke Hammer $^{1,7} \cdot$ Daniel Beug $^{2} \cdot$ Leif Steil $^{1}$ \\ Yvonne Reinke $^{2,7} \cdot$ Kerstin Weitmann $^{3,7} \cdot$ Markus Grube $^{4} \cdot$ Christiane Trimpert $^{2}$ • \\ Karin Klingel $^{5} \cdot$ Reinhard Kandolf $^{5} \cdot$ Wolfgang Hoffmann ${ }^{3,7} \cdot$ Matthias Nauck $^{6,7}$. \\ Marcus Dörr $^{2,7} \cdot$ Klaus Empen $^{2} \cdot$ Stephan B. Felix $^{2,7} \cdot$ Uwe Völker $^{1,7}$
}

Received: 10 December 2015/Accepted: 16 June 2016/Published online: 13 July 2016

(C) Springer-Verlag Berlin Heidelberg 2016

\begin{abstract}
Immunoadsorption with subsequent immunoglobulin substitution (IA/IgG) represents a therapeutic approach for patients with dilated cardiomyopathy (DCM). Here, we studied which molecular cardiac alterations are initiated after this treatment. Transcription profiling of endomyocardial biopsies with Affymetrix whole genome arrays was performed on 33 paired samples of DCM patients collected before and 6 months after IA/IgG. Therapy-related effects on myocardial protein levels were analysed by label-free proteome profiling for a subset of 23 DCM patients. Data were analysed regarding therapy-associated differences in gene expression and protein levels by comparing responders (defined by improvement of left ventricular ejection fraction $\geq 20 \%$ relative and $\geq 5 \%$ absolute) and non-responders. Responders to IA/IgG showed a decrease in serum N-terminal proBNP levels in
\end{abstract}

S. Ameling and G. Bhardwaj contributed equally.

Electronic supplementary material The online version of this article (doi:10.1007/s00395-016-0569-y) contains supplementary material, which is available to authorized users.

Stephan B. Felix

felix@uni-greifswald.de

$\triangle$ Uwe Völker

voelker@uni-greifswald.de

1 Interfaculty Institute for Genetics and Functional Genomics, University Medicine Greifswald, Friedrich-Ludwig-JahnStraße 15a, 17475 Greifswald, Germany

2 Department of Internal Medicine B, University Medicine Greifswald, Ferdinand-Sauerbruch-Straße, 17475 Greifswald, Germany

3 Institute for Community Medicine, University Medicine Greifswald, Ellernholzstr. 1-2, 17487 Greifswald, Germany comparison with baseline which was accompanied by a decreased expression of heart failure markers, such as angiotensin converting enzyme 2 or periostin. However, despite clinical improvement even in responders, IA/IgG did not trigger general inversion of DCM-associated molecular alterations in myocardial tissue. Transcriptome profiling revealed reduced gene expression for connective tissue growth factor, fibronectin, and collagen type $I$ in responders. In contrast, in non-responders after IA/IgG, fibrosis-associated genes and proteins showed elevated levels, whereas values were reduced or maintained in responders. Thus, improvement of LV function after IA/ IgG seems to be related to a reduced gene expression of heart failure markers and pro-fibrotic molecules as well as reduced fibrosis progression.

Keywords Cardiomyopathy $\cdot$ Responder $\cdot$ Fibrosis · Transcriptome Proteome

4 Department of Pharmacology, Centre of Drug Absorption and Transport (C_DAT), University Medicine Greifswald, FelixHausdorff-Str. 3, 17487 Greifswald, Germany

5 Department of Molecular Pathology, University Hospital Tübingen, Liebermeisterstr. 8, 72076 Tübingen, Germany

6 Institute of Clinical Chemistry and Laboratory Medicine, University Medicine Greifswald, Ferdinand-SauerbruchStraße, 17475 Greifswald, Germany

7 DZHK (German Centre for Cardiovascular Research), Partner Site Greifswald, Greifswald, Germany 


\section{Introduction}

Dilated cardiomyopathy (DCM) is characterised by ventricular chamber enlargement and impaired myocardial function and is one of the leading indications for heart transplantation [40]. Besides genetic predisposition, cardiac viral infections and inflammation play a causal role in the disease process $[25,34,40]$. Furthermore, autoimmune disorders resulting in activation of the cellular and humoral immune response have been implicated in the development of DCM [11, 29]. Antibodies against numerous cardiac proteins have been identified in these patients, indicating an active role in the pathogenesis by virtue of triggering the disease process or by aggravating myocardial contractile dysfunction [28, 45]. Furthermore, in asymptomatic relatives of patients with DCM, detection of cardiac autoantibodies predicts disease development $[8,9]$. The pathogenic potential of autoantibodies has been proved in animal models by active immunisation as well as by transfer of antibodies directed against the corresponding epitopes, both leading to dilation and dysfunction of the ventricle $[21,27]$. Supporting the functional role of cardiac autoantibodies in DCM, pilot studies showed that the depletion of immunoglobulins from the plasma of patients by immunoadsorption with subsequent immunoglobulin $\mathrm{G}$ substitution (IA/IgG) resulted in significant haemodynamic improvements, such as an increase in cardiac index, left ventricular ejection fraction (LVEF) as well as relief of symptoms [16, 17, 49, 50], and improvement of endothelial function [6]. Furthermore, a decrease in activated T-cells and an increase in regulatory $\mathrm{T}$-cells have been shown to be associated with haemodynamic improvement after IA/IgG, revealing a link between cellular and humoral immunity [7]. Recently, cardiac autoantibodies were also detected in a subgroup of peripartum cardiomyopathy patients and may point to similarities in some of the pathophysiological processes, thus also indicating that removal of these antibodies might be a therapeutic option not only in DCM but also in peripartum cardiomyopathy [22].

However, response rates to this therapeutic intervention are characterised by considerable inter-individual variability $[1,48]$. Hence, the molecular effects triggered by therapies are of particular interest to understand the underlying mechanisms of haemodynamic improvements. Changes in therapy-related myocardial gene expression patterns have been investigated in patients with heart failure (HF) treated with left ventricular assist device (LVAD) [23, 39] and cardiac resynchronization therapy (CRT) [42, 53]. Improvement of ventricular function was associated with significant expression changes in a set of myocardial genes involved in maintenance of contractility for CRT [53, 54] and remodelling for LVAD [19]. With respect to medical treatment, another study [37] demonstrated that in patients suffering from idiopathic DCM, improvement in LVEF after treatment with beta-blockers was associated with favourable expression changes of genes encoding sarcoplasmic-reticulum calcium ATPase $2 \alpha$ (SERCA2 $\alpha$ ) and the $\alpha$ and $\beta$ isoforms of myosin heavy chain.

Although beneficial effects of IA/IgG have been described $[16,17,49,50]$, the potential underlying mechanisms have still to be elucidated on molecular level. Therefore, in this study comparative profiling of biopsies of DCM patients before (baseline, BL) and 6 months after (follow up, FU), IA/IgG therapy was performed and effects on gene expression and protein levels were explored to gain new information on therapy-associated molecular events.

\section{Materials and methods}

\section{Study design}

This pilot study comprises 33 DCM patients with LV systolic dysfunction (LVEF $<45 \%$ ) and symptoms of chronic HF according to New York Heart Association (NYHA) functional classes II and III which underwent IA/IgG in the University Hospital Greifswald between 2004 and 2008. Patients had not suffered from active infectious diseases, cancer, chronic alcoholism, postpartum cardiomyopathy, or HF due to known origins (e.g. primary valvular disease). All patients received stable oral medication for $\mathrm{HF}$ according to ESC guidelines [13, 47, 52] and medication was kept stable for the duration of this study with exception of dose adjustments for diuretics (Table 1, see Online Resource Supplemental Material ESM 1). Among all patients, we excluded coronary heart disease by angiography as well as acute myocarditis by endomyocardial biopsy (EMB), in accordance with Dallas criteria and immunohistological stainings [2, 12, 31, 38]. Myocardial biopsies were obtained for clinical reasons for diagnosis of DCM according to guidelines [12, 47] and for assessment of myocardial infections and inflammation after IA/IgG at baseline and during follow-up after 6 months (follow-up, FU). Transcriptome ( $n=33$ ) and proteome (subset, $n=23$ ) analyses were performed from endomyocardial biopsies which were no longer needed for routine diagnostics.

\section{Immunoadsorption and subsequent immunoglobulin G substitution}

In all patients, IA was performed on five consecutive days using protein-A columns (Immunosorba ${ }^{\circledR}$, Fresenius Medical Care AG, Bad Homburg, Germany) with a 
Table 1 Baseline characteristics of DCM patients

\begin{tabular}{|c|c|c|c|}
\hline & Responder $(n=20)$ & Non-responder $(n=13)$ & $\begin{array}{l}\text { Responder vs. non-responder } \\
p \text { value }\end{array}$ \\
\hline Age (years) $\pm \mathrm{SD}^{\mathrm{a}}$ & $48 \pm 10$ & $53 \pm 8$ & $0.145^{\mathrm{e}}$ \\
\hline Gender $(\delta / P)$ & $14 / 6$ & $12 / 4$ & $1.000^{\mathrm{f}}$ \\
\hline $\operatorname{LVEF}(\%) \pm \mathrm{SD}^{\mathrm{a}}$ & $33 \pm 6$ & $35 \pm 7$ & $0.406^{\mathrm{e}}$ \\
\hline $\operatorname{LVIDD}(\mathrm{mm}) \pm \mathrm{SD}^{\mathrm{a}}$ & $67 \pm 7$ & $74 \pm 7$ & $0.022^{\mathrm{e}}$ \\
\hline NYHA classification II/III $(n)$ & $10 / 10$ & $7 / 6$ & $1.000^{\mathrm{e}}$ \\
\hline NT-pro BNP $(\mathrm{pg} / \mathrm{ml}) \pm \mathrm{SD}^{\mathrm{a}}$ & $1035 \pm 1372$ & $1047 \pm 992$ & $0.428^{\mathrm{e}}$ \\
\hline Disease duration (months) $\pm \mathrm{SD}^{\mathrm{a}}$ & $13 \pm 13$ & $49 \pm 42$ & $0.003^{\mathrm{e}}$ \\
\hline Body mass index $\left(\mathrm{kg} / \mathrm{m}^{2}\right) \pm \mathrm{SD}^{\mathrm{a}}$ & $28 \pm 5$ & $27 \pm 4$ & $0.645^{\mathrm{e}}$ \\
\hline Inflammation positive $(n)^{\mathrm{b}}$ & 14 & 8 & $0.714^{\mathrm{f}}$ \\
\hline Fibrosis grade ${ }^{c}(n) 0 / 1 / 2 / 3$ & $0 / 12 / 4 / 4$ & $0 / 4 / 4 / 5$ & $0.25^{\mathrm{g}}$ \\
\hline Virus genomes PVB19/PVB19+HHV6/other ${ }^{\mathrm{d}}(n)$ & $4 / 1 / 15$ & $4 / 0 / 9$ & \\
\hline \multicolumn{4}{|l|}{ Medication $(n /$ total $)$} \\
\hline$\beta$-Blocker & $20 / 20$ & $13 / 13$ & \\
\hline ACE inhibitors and/or & $16 / 20$ & $11 / 13$ & \\
\hline AT1 antagonists & $5 / 20$ & $5 / 13$ & \\
\hline Diuretics & $20 / 20$ & $13 / 13$ & \\
\hline Digitalis & $2 / 20$ & $5 / 13$ & \\
\hline
\end{tabular}

LVEF left ventricular ejection fraction, $L V I D D$ left ventricular internal diameter at diastole, NYHA New York Heart association, NT-pro BNP $\mathrm{N}$-terminal, pro brain natriuretic peptide, $P V B 19$ parvovirus B19, ACE angiotensin converting enzyme, AT1 angiotensin-II-receptor-subtype-1

${ }^{\text {a }}$ Mean values with standard deviation (SD) are shown

${ }^{\mathrm{b}}$ Endomyocardial biopsies were considered to be inflamed if immunohistochemistry revealed focal or diffuse mononuclear infiltrates with $>14$ leucocytes per $\mathrm{mm}^{2}$ (CD3 ${ }^{+}$T-lymphocytes and/or CD68 ${ }^{+}$macrophages) in addition to enhanced expression of HLA class II molecules [31, 38]

c The amount of cardiac fibrosis in HEMBs was determined and categorised as grade $0=$ no, grade $1=$ mild, grade $2=$ moderate, grade $3=$ severe

d Other virus types: HHV6 human herpesvirus 6, EBV Epstein-Barr virus, Enteroviruses

e Mann-Whitney test, two-tailed

${ }^{\mathrm{f}}$ Fisher's exact test, two-tailed

g Chi-square test

treatment regime described elsewhere [49]. After the final immunoadsorption session, patients received $0.5-\mathrm{g} / \mathrm{kg}$ human intravenous immunoglobulins (Venimmun, Sandoglobulin, CSL Behring, Germany, or Octagam, Octapharma, Switzerland) to restore physiological IgG plasma levels [49]. Patients displaying an increase of $\geq 5 \%$ in the absolute LVEF value (5 LVEF units) and $\geq 20 \%$ relative to the LVEF at BL were classified as responders (R), while those not fulfilling these criteria were defined as non-responders (NR).

\section{Echocardiography}

Echocardiographic parameters [LVEF according to Simpson rule and left ventricular internal diameter at diastole (LVIDD)] were determined by two independent physicians by two-dimensional echocardiography, performed at BL and FU 6 months after IA/IgG as described previously [1].

\section{Brain natriuretic peptide}

$\mathrm{N}$-terminal pro-brain natriuretic peptide (NT-pro BNP) was determined in serum on a Siemens Dimension Vista ${ }^{\circledR} 1500$ System using an in vitro diagnostic assay based on $\mathrm{LOCI}^{\circledR}$ technology (Siemens Healthcare Diagnostics Inc., Newark, USA).

\section{Histological and immunohistological analyses and detection of viral genomes}

Five endomyocardial biopsies were fixed in $4 \%$ buffered formaldehyde for histology and immunohistology or were fixed in RNAlater (Ambion Inc., Foster City, USA) for detection of viral genomes by nested real-time polymerase chain reaction (qRT-PCR). Histological analysis for the diagnosis of myocarditis followed the Dallas criteria complemented by immunohistology to assess inflammation 
as described [31, 38, 41]. Inflammation was considered present after immunohistological detection of mononuclear infiltrates with $14 \mathrm{CD}^{+} \mathrm{T}$ cells/and or $\mathrm{CD}^{+} 8^{+}$macrophages per $1 \mathrm{~mm}^{2}$ in the myocardium, in addition to enhanced expression of HLA class II molecules.

\section{Fibrosis}

The extent of myocardial fibrosis in EMB was determined from samples immediately fixed under sterile conditions in $4 \%$ buffered formaldehyde by routine light microscopy examination using Masson's trichrome staining. The extent of myocardial fibrosis in EMB was defined as an index as described previously [58]. The percentage area of fibrosis in the section was evaluated by dividing the sum of fibrotic areas of the section by that of the total tissue area. According to this fibrosis index, patients were classified as having no (grade 0 ), mild (grade 1 ), moderate (grade 2 ), or severe fibrosis (grade 3).

\section{Transcriptome analyses}

EMBs (3-4 samples) from each patient were pooled, and homogenised. From a portion of tissue powder, RNA was isolated following the manufacturer's instructions for total RNA isolation from fibrous tissues (RNeasy ${ }^{\circledR}$ Micro Kit, Qiagen Inc., Valencia, USA). After purification and quality assessment, transcriptional profiling of EMBs was performed with GeneChip-Human Genome-HG U133-Plus 2.0-arrays (Affymetrix, Santa Clara, USA) as described recently [1]. Expression raw data were transferred to Rosetta Resolver ${ }^{\circledR} 7.2$ (Ceiba Solutions, Seattle, USA.) for probe set extraction and normalisation. For further analyses, filtering was based on probe sets having signals above background intensity $(p<0.05)$ in at least $80 \%$ of one of the classes compared. In the initial phase of the study, the validity of the microarray data were confirmed by conducting qRT-PCR of selected genes in a subset of patients (9 responders, 5 non-responders) using a custom-manufactured TaqMan low density array (see Online Resource ESM 1).

\section{Proteome analyses}

For 23 patients (R: $n=12$, NR: $n=11$ ), remaining EMB tissue powders were also sufficient for proteome analysis. Protein extraction, determination of concentration, and sample preparation for mass spectrometry (MS) were performed as described earlier [24]. Briefly, relative quantitation of therapy effects on protein levels was based on label-free MS analyses of tryptic peptide extracts of each patient and time point. After alignment of signals across all MS runs, signal intensities as quantitative measures were extracted and assigned to peptides and proteins by a Uniprot_SProt database search (see Online Resource ESM 1).

\section{Statistical analyses and functional classification}

For determination of $\mathrm{IA} / \mathrm{IgG}$-related alterations on gene expression, the ratios of probe set signals at FU and BL per patient were calculated, allowing reduction of the effects of inter-individual variability at BL. Therapy effects were calculated using the rank product-based statistics method [5] using 1000 permutations, generating for each probe set an average ratio and two false discovery rate $(q)$ values [51] for upregulation (FU/BL >1) and downregulation (FU/ $\mathrm{BL}<1$ ) for each group (R or NR), respectively (Fig. 1a, b). The same algorithm was applied to compare ratios of responders and non-responders (R FU/BL vs. NR FU/BL) (Fig. 1c). Probe sets with significant $(q<0.05)$ upregulation (R FU/BL $>$ NR FU/BL) or downregulation (R FU/ $\mathrm{BL}<\mathrm{NR}$ FU/BL) were considered differentially affected by IA/IgG and selected for further analysis. Gene expression data were also analysed with adjustment for inflammation and fibrosis (see Online Resource ESM 1). IA/IgGassociated changes on protein level were calculated as described above except no multiple test correction was applied due to the lower number of molecules in the analyses and a fold change filter (FC) of 1.3 was used.

The descriptive statistics of clinical parameters are expressed as mean with standard deviation (SD). Mann-

Analysis type I: subgroup specific expression changes
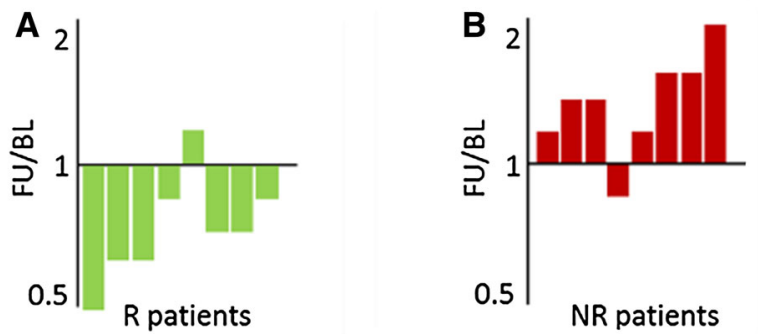

Analysis type II: differences between subgroups
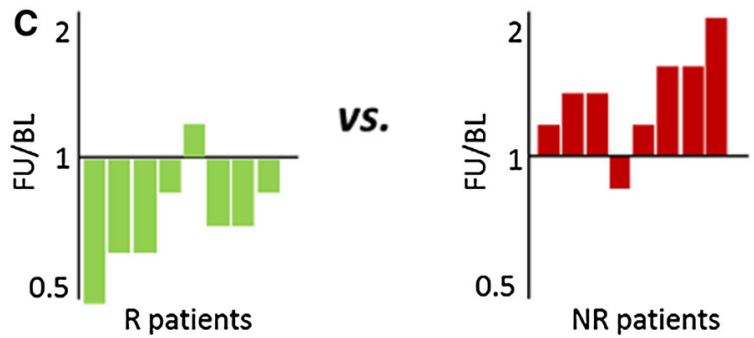

Fig. 1 Schematic overview of analyses. Exemplarily, an altered gene/protein level per patient-as indicated by follow-up (FU) vs. baseline (BL) ratios per patient (bar) for a responders (R) and b nonresponders (NR), was shown. To define differences between subgroups, ratios of responders and non-responders were compared with each other (c) 
Whitney test, Fisher's exact test, Wilcoxon-signed rank test, and Pearson's Chi-square test were used for appropriate comparisons.

Ingenuity Pathway Analysis (Ingenuity Systems, Redwood City, USA; http://www.ingenuity.com) was used for functional assignments of differentially expressed genes and altered proteins. Expression data have been submitted to the NCBI gene-expression and hybridization-array data repository (GEO).

\section{Results}

\section{Baseline characteristics of patients}

Clinical BL characteristics of all patients are summarised in Table 1. LVEF and NYHA classes showed no significant difference at BL between responders and non-responders, but patient groups significantly differed in LVIDD $(p=0.022)$ and disease duration $(p<0.003)$. Serum levels of the heart failure marker NT-pro BNP as well as inflammation, virus detection, and fibrosis findings from EMBs of responders and non-responders did not differ significantly between both groups.

\section{Clinical findings and haemodynamic changes after immunoadsorption and subsequent immunoglobulin $\mathbf{G}$ substitution}

IA/IgG treatment was tolerated well by all 33 patients, and no serious events occurred. Immunoglobulin $\mathrm{G}$ levels were reduced by $94.7 \pm 2 \% 5$ days after IA, with no significant difference in subgroups (responders $95.4 \pm 1 \%$, non-responders $94.1 \pm 3 \%$ ). In the responder group, LVEF increased from $33 \pm 6 \%$ at $\mathrm{BL}$ to $47 \pm 6 \%$ after 6 months $(p<0.001)$. Simultaneously, LVIDD decreased from $67 \pm 7$ to $60 \pm 7 \mathrm{~mm}(p<0.001)$, and NYHA class improved from NYHA class III/II to II/I $(p=0.021)$. In contrast, $\mathrm{LVEF}(35 \pm 7 \%$ at $\mathrm{BL}$ to $36 \pm 8 \%$ at $\mathrm{FU}$ ) and LVIDD (74 $\pm 7 \mathrm{~mm}$ at BL to $73 \pm 9 \mathrm{~mm}$ at FU) remained almost unchanged in non-responders (Table 2). Moreover, the number of patients with myocardial inflammation decreased significantly among the responders from BL $(n=14)$ to $\mathrm{FU}(n=6, p=0.026)$, and serum NT-pro BNP level was significantly decreased (1035 to $463 \mathrm{pg} / \mathrm{ml}$, $p<0.004)$ in this group 6 months after treatment compared with BL (Fig. 2). In non-responders, these parameters did not change significantly. The grade of fibrosis in Masson Trichrome stained EMB tissue sections as

Table 2 Longitudinal characteristics of IA/IgG population

\begin{tabular}{|c|c|c|c|c|c|c|}
\hline & \multicolumn{3}{|c|}{ Responder $(n=20)$} & \multicolumn{3}{|c|}{ Non-responder $(n=13)$} \\
\hline & $\mathrm{BL}$ & $\mathrm{FU}$ & $p^{\mathrm{d}}$ & BL & FU & $p^{\mathrm{d}}$ \\
\hline \multicolumn{7}{|c|}{ Subgroup specific differences after IA/IgG } \\
\hline $\operatorname{LVEF}(\%) \pm \mathrm{SD}^{\mathrm{a}}$ & $33 \pm 6$ & $47 \pm 6$ & $<0.001$ & $35 \pm 7$ & $36 \pm 8$ & 0.344 \\
\hline $\operatorname{LVIDD}(\mathrm{mm}) \pm \mathrm{SD}^{\mathrm{a}}$ & $67 \pm 7$ & $60 \pm 7$ & $<0.001$ & $74 \pm 7$ & $73 \pm 9$ & 0.586 \\
\hline $\mathrm{NT}$-pro BNP pg/ml $\pm \mathrm{SD}^{\mathrm{a}}$ & $1035 \pm 1372$ & $463 \pm 923$ & $<0.004$ & $1047 \pm 992$ & $1196 \pm 1211$ & 0.839 \\
\hline Inflammation positive $(n)^{\mathrm{b}}$ & 14 & 6 & $0.026^{\mathrm{e}}$ & 8 & 9 & $1.000^{\mathrm{e}}$ \\
\hline NYHA I/II/III/IV $(n)$ & $0 / 10 / 10 / 0$ & $6 / 9 / 5 / 0$ & $0.021^{\mathrm{f}}$ & $0 / 7 / 6 / 0$ & $2 / 8 / 3 / 0$ & $0.216^{\mathrm{f}}$ \\
\hline Fibrosis $\operatorname{grade}^{\mathrm{c}} 0 / 1 / 2 / 3(n)$ & $0 / 12 / 4 / 4$ & $0 / 12 / 5 / 3$ & $0.838^{\mathrm{f}}$ & $0 / 4 / 4 / 5$ & $0 / 3 / 5 / 5$ & $0.806^{\mathrm{f}}$ \\
\hline \multicolumn{7}{|c|}{ Differences between subgroups after IA/IgG } \\
\hline$\Delta \mathrm{LVEF}(\%) \pm \mathrm{SD}^{\mathrm{a}}$ & & $13 \pm 6$ & & & $1 \pm 4$ & $<0.001^{\mathrm{g}}$ \\
\hline$\Delta \mathrm{LVIDD}(\mathrm{mm}) \pm \mathrm{SD}^{\mathrm{a}}$ & & $-7 \pm 5$ & & & $0 \pm 3$ & $<0.001^{\mathrm{g}}$ \\
\hline$\Delta \mathrm{NT}$-pro BNP pg/ml $\pm \mathrm{SD}^{\mathrm{a}}$ & & $-572 \pm 1099$ & & & $148 \pm 813$ & $0.172^{\mathrm{g}}$ \\
\hline \multicolumn{7}{|c|}{$L V E F$ left ventricular ejection fraction, $L V I D D$ left ventricular internal diameter at diastole, NYHA New York Heart Association } \\
\hline \multicolumn{7}{|c|}{$\begin{array}{l}\text { b Myocardial biopsies were considered to be inflamed if immunohistochemistry revealed focal or diffuse mononuclear infiltrates with }>14 \\
\text { leucocytes per } \mathrm{mm}^{2}\left(\mathrm{CD}^{+} \text {T-lymphocytes and/or CD68 }{ }^{+} \text {macrophages) in addition to enhanced expression of HLA class II molecules [31, 38] }\right.\end{array}$} \\
\hline \multicolumn{7}{|c|}{$\begin{array}{l}\text { The amount of cardiac fibrosis in HEMBs was determined and categorised as grade } 0=\text { no, grade } 1=\text { mild, grade } 2=\text { moderate, grade } \\
3=\text { severe }\end{array}$} \\
\hline \multicolumn{7}{|c|}{${ }^{\mathrm{d}} p$ value baseline $(\mathrm{BL})$ vs. follow up (FU) of responders and non-responders is based on Wilcoxon-signed rank test } \\
\hline \multicolumn{7}{|l|}{ e Fisher's exact test, two-tailed } \\
\hline${ }^{\mathrm{f}}$ Chi-square test & & & & & & \\
\hline
\end{tabular}



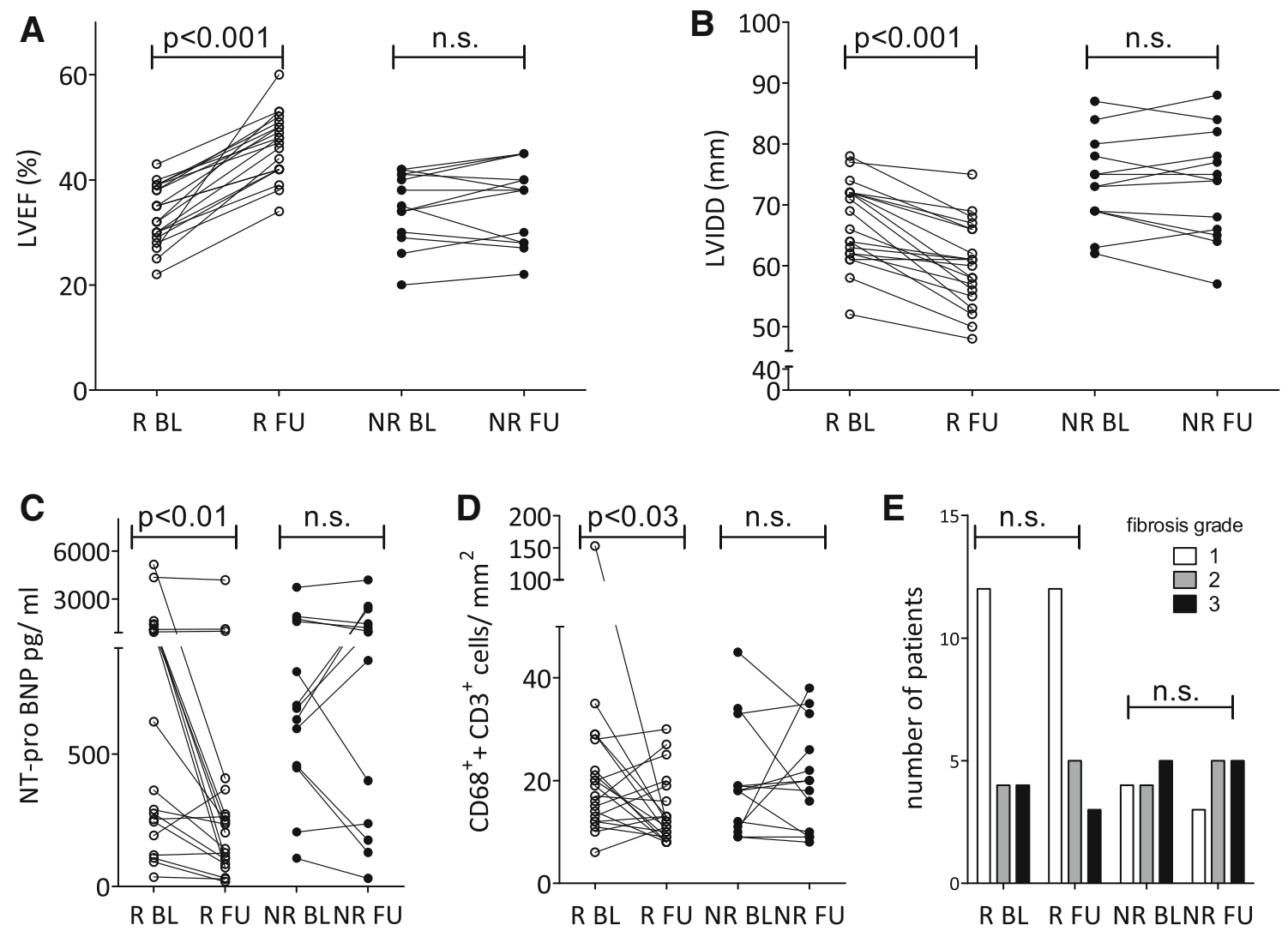

Fig. 2 Individual changes in a LVEF, b LVIDD, c NT-pro BNP plasma levels, $\mathbf{d}$ inflammation as indicated by infiltrated leucocytes $\left(\mathrm{CD}^{+}{ }^{+} \mathrm{T}\right.$-lymphocytes and/or CD68 ${ }^{+}$macrophages) $[(\mathbf{a}-\mathbf{d}) p$ value

evaluated by light microscopy did not change in any of the two groups after IA/IgG (Table 2). Individual patient data are shown in Fig. 2.

\section{Changes in myocardial gene expression and protein levels in responders and non-responders after IA/ IgG}

Responders and non-responders were analysed separately (Fig. 1a, b) to elucidate gene expression changes after IA/ IgG. In general, more genes were altered in responders (244 genes, mean of individual $\mathrm{FU}$ over $\mathrm{BL}$ ratios $\mathrm{FC} \geq 11.2 \mathrm{l}, q<0.05)$ after $\mathrm{IA} / \mathrm{IgG}$ therapy than in nonresponders (129 genes, see Online Resource Supplemental Tables ESM 2, ESM 3). Functional assignment of genes altered significantly in expression levels at FU compared with BL in the respective subgroup revealed largely different categories or a different level of alterations for responders and non-responders (Fig. 3a, c). In responders, preferentially genes of the categories skeletal and muscular system development and function (42 genes) and connective tissue development and function (41 genes) were altered after therapy. For the majority of the respective genes, lower expression was found in responders after IA/ derived by Wilcoxon-signed rank test, for both subgroups)], and e fibrosis grade after IA/IgG (Chi-square test, for both subgroups, $n s$. not significant)

IgG compared with BL (Fig. 3b, Online Resource Supplemental Table ESM 4).

Significantly lower gene expression was observed for periostin (POSTN), angiotensin converting enzyme 2 (ACE2), and the connective tissue growth factor (CTGF) at FU compared with $\mathrm{BL}$ in responders, whereas, in non-responders, the expression of these genes remained unchanged or even increased (Fig. 4). Transcripts of natriuretic peptides A (NPPA) and B (NPPB) showed the same declining trend in responders (Fig. 4), indicating a slightly better status after therapy compared with non-responders.

qRT-PCR analysis for a subset of patients revealed the same significant decrease for both natriuretic peptides ANP, $\mathrm{BNP}$, and ACE2 in responders $(n=9)$, but not in non-responders $(n=5)$ (Online Resource ESM 5 Supplemental Fig. S1), supporting the microarray data (Fig. 4). Microarray data (see Online Resource Supplemental Tables ESM 2, ESM 3) were also confirmed for natriuretic peptide receptor 3 (NPR3) and CORIN, whereas data for periostin (POSTN) were not confirmed by qRT-PCR in the smaller subset.

Further inverse regulation upon $\mathrm{IA} / \mathrm{IgG}$ in responders and non-responders was observed for additional six genes, including chemokine (C-X-C motif) ligand 11 (CXCL11), golgi glycoprotein 1 (GLG1), iroquois homeobox 1 
POSTN

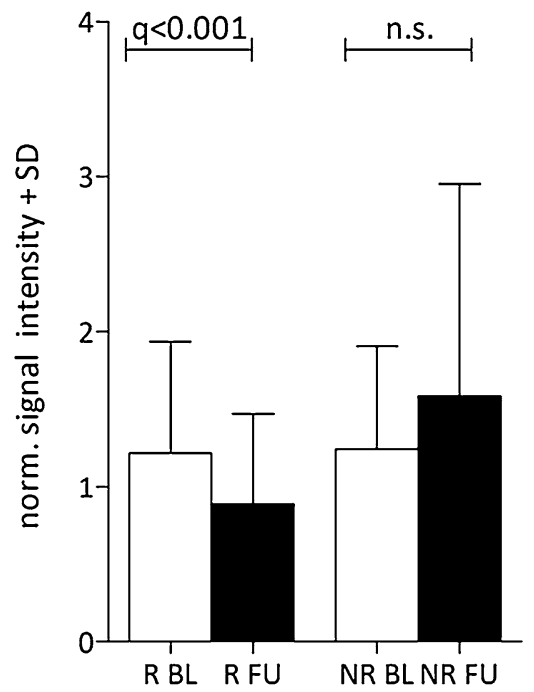

NPPA

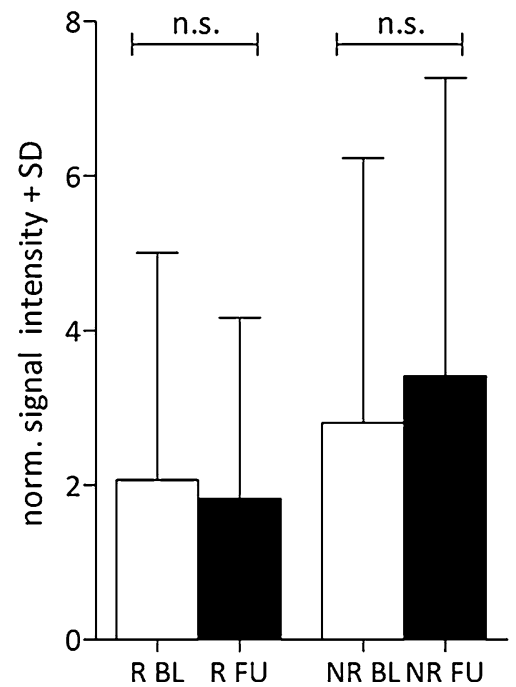

ACE2

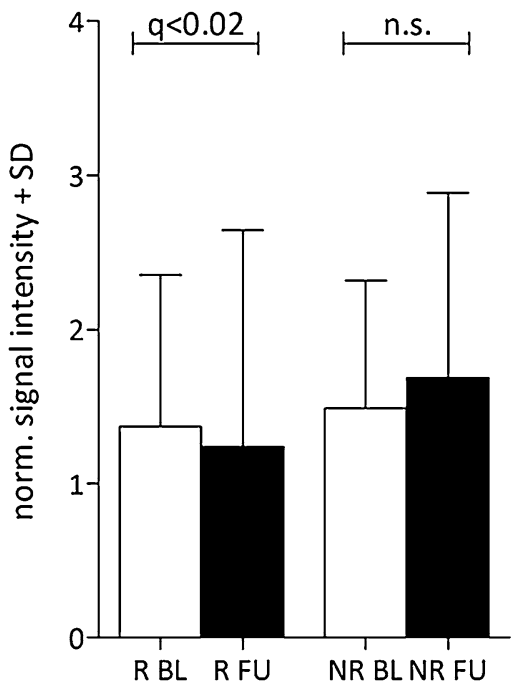

NPPB

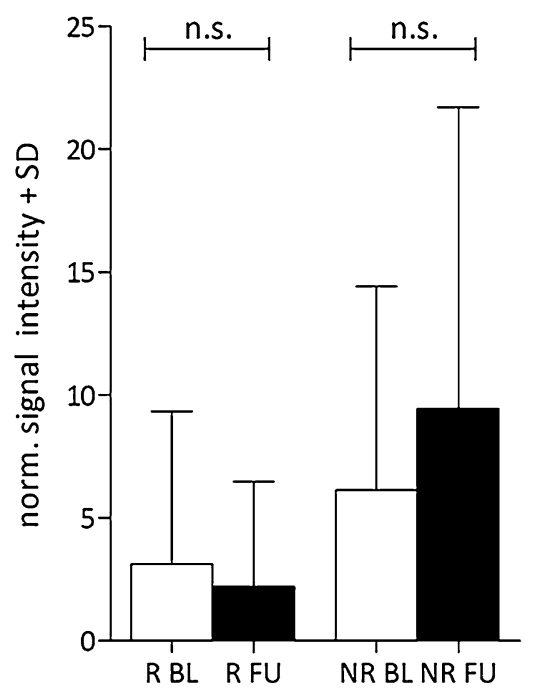

CTGF

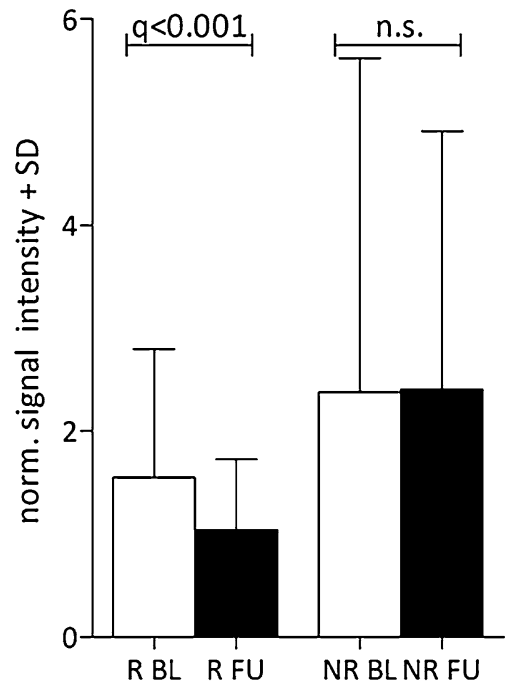

Corin

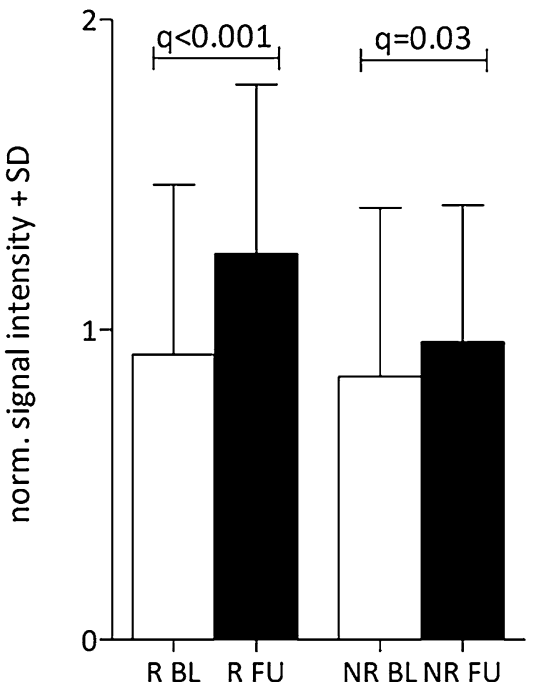

Fig. 3 Altered gene expression of HF markers in responder (R) and non-responder (NR) before (BL) and after (FU) IA/IgG therapy. Mean signal intensities and standard deviation were depicted for POSTNperiostin, ACE2 - angiotensin converting enzyme, CTGF- connective tissue growth factor, NPPA-atrial natriuretic factor and NPPB-brain natriuretic peptide for responders (R, $n=20)$ and nonresponders (NR, $n=13$ ) (rank product test, $q$ FDR-value, rank product test, $n s$. not significant)
(IRX1), mitochondrial ribosomal protein $\mathrm{S} 18 \mathrm{C}$ (MRPS18C), peripheral myelin protein 2 (PMP2), and hyaluronan and proteoglycan link protein 1 (HAPLN1) (see Online Resource ESM 5 Supplemental Fig. S2).

Of the genes affected in expression level by IA/IgG (R: 244 genes, NR: 129 genes), 10 genes including CORIN (see Online Resource ESM 5 Supplemental Fig. S2) displayed a conserved effect in responders and non-responders.

By functional assignment of genes altered significantly in expression levels at FU compared with BL in non-responders, the highest significance was observed for haematological system development and function (38 genes), immune cell trafficking (28 genes), and cardiovascular system development and function (25 genes) categories which were also affected but to a lesser degree in responders (Fig. 3c, Online Resource Supplemental Table ESM 6). Since, in non-responders, no changes in LVEF were observed, these alterations do not seem to be associated with improvement of heart function. In total, IA/ IgG-associated gene expression changes pointed to a rather diverse pattern than an alteration of a defined pathway. Since inflammation and fibrosis are known parameters 
A

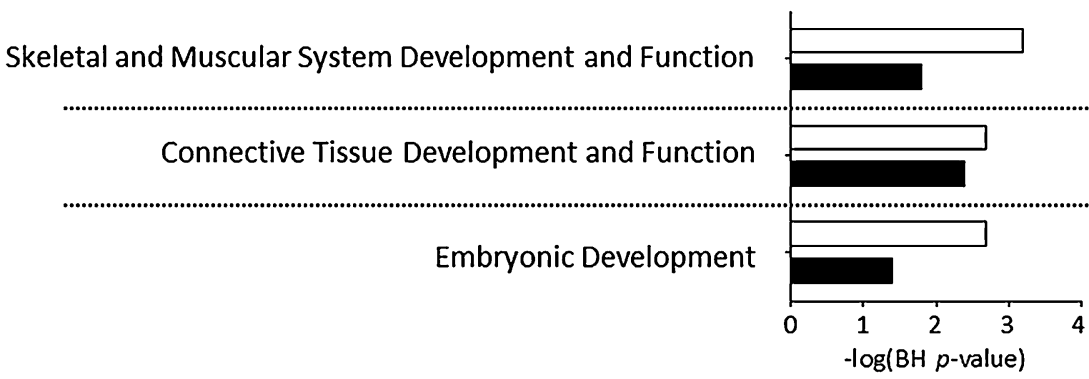

C
B repressed induced

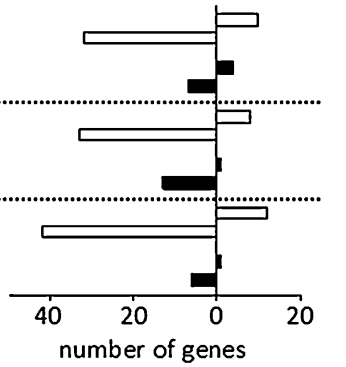

D repressed induced

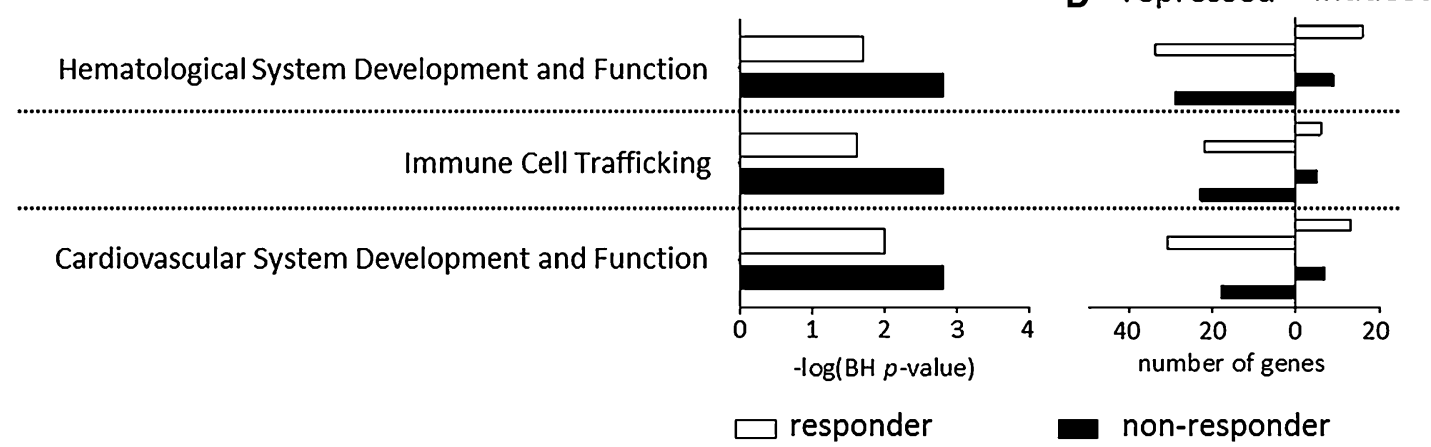

Fig. 4 Functional assignment of genes regulated in responders (R) and non-responders (NR) after IA/IgG ( $\mid 1.2 \mathrm{l}, q<0.05$, responder 244 genes, and non-responders 129 genes). Top 3 enriched categories of physiological system development and function and direction of regulated genes in responders $(\mathbf{a}, \mathbf{b})$ and non-responders $(\mathbf{c}, \mathbf{d})$ are

associated with DCM progression and affected by IA/IgG (Table 2), data were adjusted for these cofactors to screen for effects independent of these two cofactors. We observed a stronger influence of the adjustment for inflammation and fibrosis on the data of responders compared with non-responders (see Online Resource ESM 5 Supplemental Fig. S3). The adjustment for the factors inflammation or fibrosis revealed a decrease in the number of significantly regulated genes and the corresponding $p$ values in responders but triggered only marginal changes in non-responders. Functional categorization of the genes remaining after adjustment (see Online Resource ESM 7 and ESM 8) did not reveal hints for other pathways targeted by IA/IgG in any of the two patient subgroups.

Alterations on protein level were only minor in responders (16 proteins) and non-responders (43 proteins, see Online Resource ESM 9 and ESM 10, respectively). Notably, in responders, an increase in prostaglandin D2 synthase abundance was observed and confirmed, thereby, the microarray data.

\section{Subgroup specific differences in ECM remodelling after IA/IgG}

To gain a better insight into the molecular alterations triggered by $\mathrm{IA} / \mathrm{IgG}$ in the two patient subgroups, we

displayed. Data of both patient groups are shown comparatively (white bars $\mathrm{R}$; black NR). Significance $(-\log \mathrm{BH} p$ value) of the association, which is dependent on the number of genes in the class, was Benjamini-Hochberg (BH) corrected as assigned by Ingenuity Pathways Analysis

compared the magnitude of the gene expression/protein abundance changes after IA/IgG of responders and nonresponders (Fig. 1c).

Comparison of $\mathrm{FU}$ over $\mathrm{BL}$ ratios of both subgroups revealed significantly different alterations upon $\mathrm{IA} / \mathrm{IgG}$ in 320 genes $(q<0.05, \mathrm{FC} \geq|1.2|$, see Online Resource Supplemental Table ESM 11). Functional classification of those genes highlighted the following categories of molecular and cellular function: cellular assembly and organisation (25 genes); function and maintenance (33genes); and cellular movement (77 genes) (see Online Resource Supplemental Table ESM 12). Among the canonical pathways, the difference was most pronounced for genes associated with fibrosis (Fig. 5a).

Responders displayed significantly lower expression after therapy compared with $\mathrm{BL}$ (ratio $\mathrm{FU} / \mathrm{BL}<1$ ), whereas, in non-responders, expression was higher after therapy compared with $\mathrm{BL}$ (ratio FU/BL $>1$ ) for fibrosisassociated genes, such as collagen 1A2 (COL1A2), collagen 3A1 (COL3A1), biglycan (BGN), and connective tissue growth factor (CTGF) (Fig. 6), indicating lower expression of pro-fibrotic genes after IA/IgG in responders. These findings are in line with the appearance of cellular assembly and organisation as the most significant biological function highlighting additional genes encoding extracellular matrix proteins (e.g. versican, dermatopondin, 
Fig. 5 Differentially affected canonical pathways after IA/ IgG in responders and nonresponders. Functional assignment of differentially affected genes (a) and proteins (b) points to a different response of subgroups in fibrotic pathway. Significance $(-\log$ $p$ value) of the association, which is dependent on the number of genes/proteins in the class, as assigned by ingenuity pathways analysis
A

Transcriptome

\# molecules

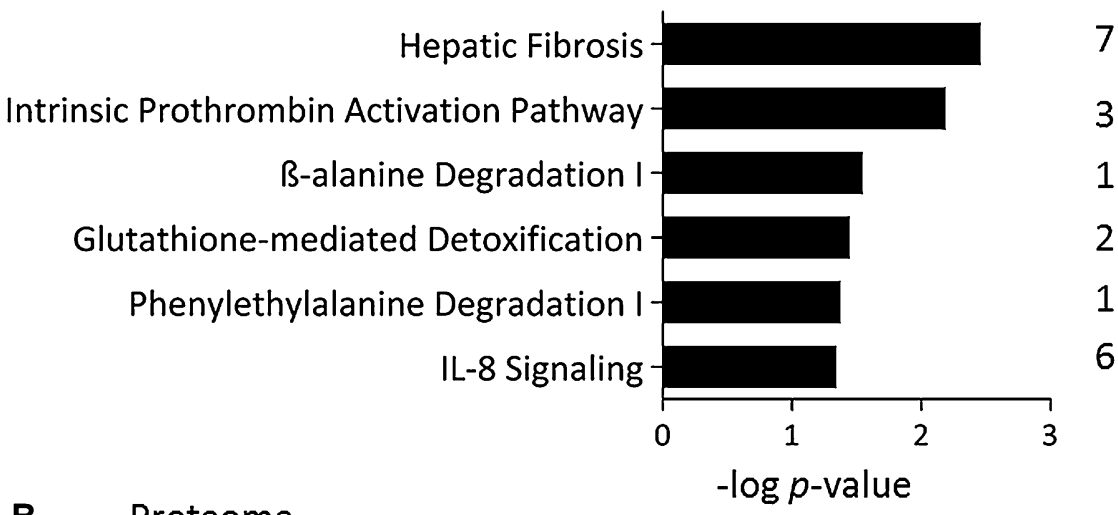

B Proteome

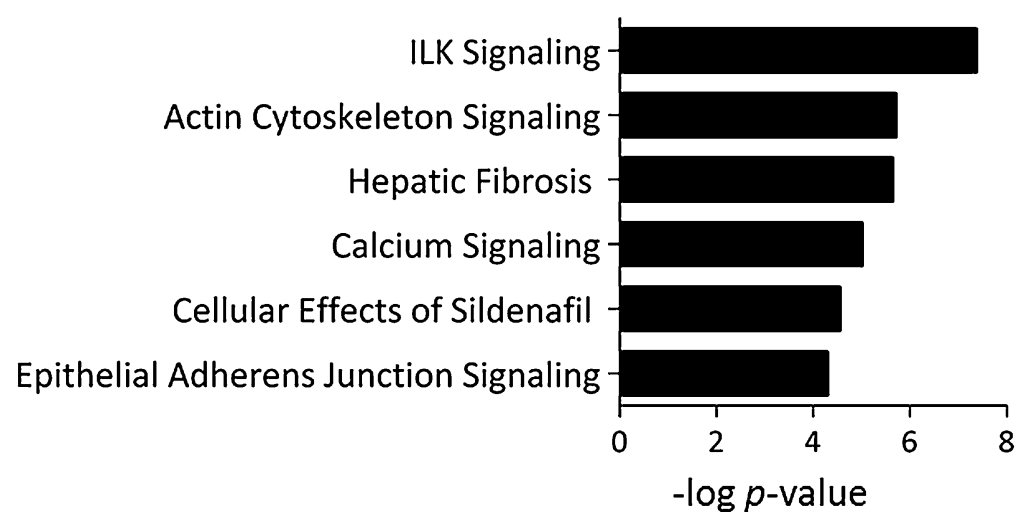

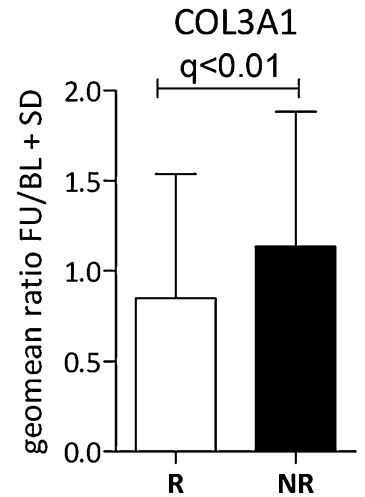

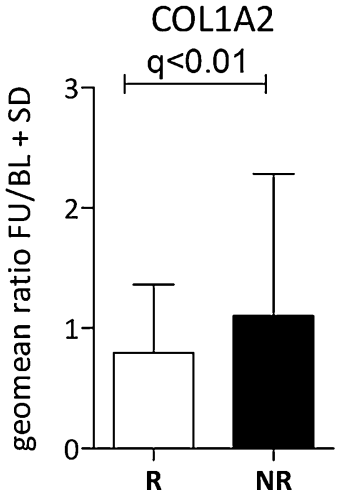

Fig. 6 Fibrosis-associated genes of responder and non-responder groups. Geometric mean of ratio intensity data (FU/BL) and standard deviation $(\mathrm{SD})$ were calculated for the subgroups responder $(\mathrm{R})$ and

collagen 5A2) and indicating differences among subgroups in extracellular matrix remodelling processes after IA/IgG.

Significant differences in protein ratios (FU/BL) between responders and non-responders were observed for 57 proteins ( $\mathrm{FC} \geq|1.3|, p<0.001$ ) (see Online Resource Supplemental Table ESM 13). Functional assignment of those proteins revealed enrichment for, e.g. integrin linked kinase (ILK) signalling, calcium signalling, actin cytoskeleton signalling as well as fibrosis (Fig. 5b, see
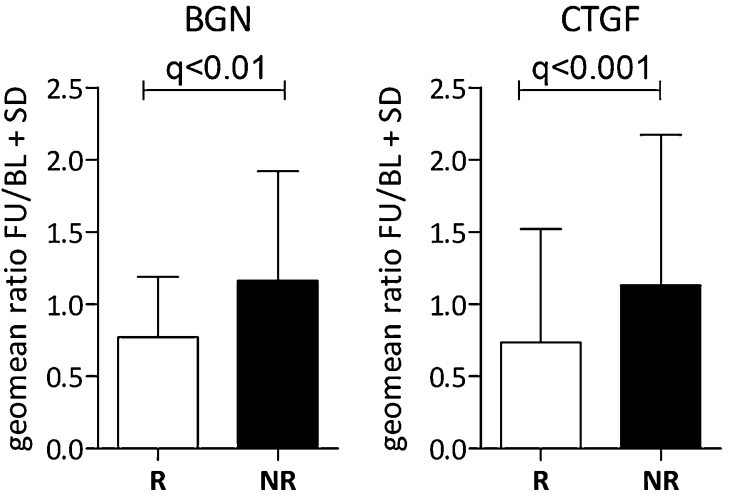

non-responder (NR) and displayed for collagen 3A1 (COL3A1), collagen 1A2 (COL1A2), biglycan (BGN), and connective tissue growth factor (CTGF) (rank product test, $q$ FDR value)

Online Resource Supplemental Table ESM 14). In concordance with the gene expression results, significantly lower ratios were observed for fibrosis-associated proteins in responders than in non-responders ( $\mathrm{R} \mathrm{FU/BL}<\mathrm{NR}$ FU/ $\mathrm{BL})$. Among them, collagen 1A1, lumican, prolargin, and biglycan were found, indicating strong IA/IgG-dependent differences in regulation of extracellular matrix components in the two subgroups (Fig. 7, Online Resource Supplemental Table ESM 13). Differences were also observed 
Fig. 7 Selected proteins in the responder and non-responder groups. Geometric mean of ratio intensity data (FU/BL) and standard deviation of collagen $1 \mathrm{~A} 1$, lumican, periostin, prolargin, biglycan, and myosin light chain 7 were compared and displayed for the subgroups responder $(\mathrm{R}, n=12)$ and nonresponder (NR, $n=11)$ (rank product test, $\mathrm{R}$ FU/BL vs. NR FU/BL, $q$ FDR value)
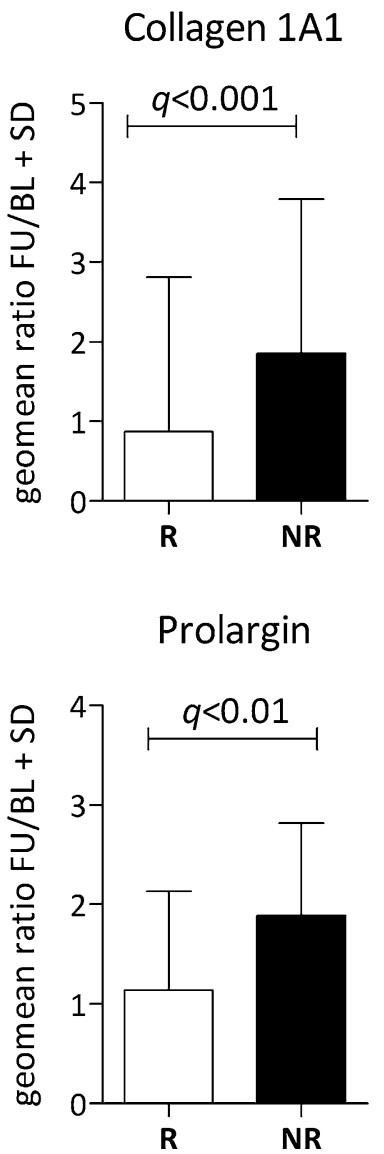

for cAMP-dependent protein kinase A, catalytic subunit beta, and myosin regulatory light chain 7 (R FU/BL $>$ NR FU/BL) but not myosin heavy chain 6 or 7 . Significantly lower ratios ( $\mathrm{R}$ FU/BL $<\mathrm{NR}$ FU/BL) were observed in responders for myosin heavy chain 11 and myosin regulatory light chain 9. Furthermore, proteome data confirmed transcriptome data for periostin.

\section{IA/IgG-associated changes in transforming growth factor beta signalling in responders}

Based on the observed IA/IgG-associated changes in gene expression and protein levels in the EMBs of responders and non-responders as well as the differences between the two subgroups at FU, an analysis with the Ingenuity Pathway Analysis suite predicted a lower expression/activity of transforming growth factor beta in responders than in non-responders (see Online Resource ESM 5 Supplemental Fig. S4). In line with this prediction, latent transforming growth factor binding protein 2 displayed decreased levels in responders 6 months after IA/IgG, whereas no significant change in levels was observed in non-responders. Table 3 summarises the different changes after $\mathrm{IA} / \mathrm{IgG}$ on transforming growth factor dependent molecules in responders and non-responders.
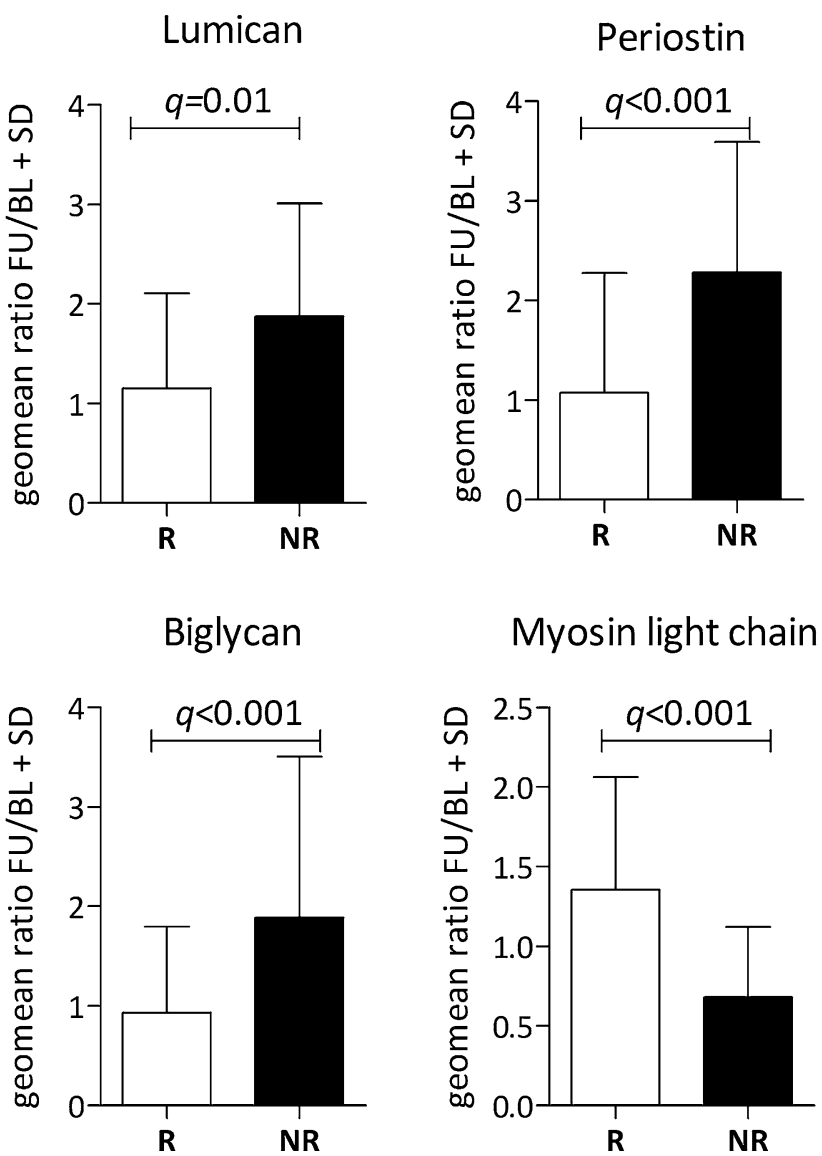

Myosin light chain 7

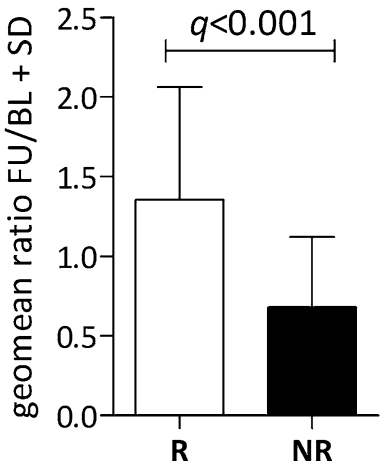

\section{Discussion}

Immunoadsorption with subsequent IgG substitution represents a therapeutic approach for the treatment of patients with DCM. Several studies on IA/IgG showed beneficial effects on myocardial and endothelial function [7, 16, 32, 49, 50]. However, response to this therapeutic intervention shows wide inter-individual variability [1]. The molecular mechanisms that explain the variability in response to therapy of DCM patients still remain to be elucidated. This is the first report addressing IA/IgG-related changes in the myocardium at the molecular level by performing transcriptomic and proteomic profiling.

\section{Changes in DCM-related myocardial gene expression in responders and non-responders upon IA/IgG therapy}

A recent profiling of myocardial gene expression patterns of responders and non-responders at baseline before IA/ IgG in comparison with control individuals revealed differential expression between responders and non-responders for genes assigned to oxidative phosphorylation, mitochondrial dysfunction, hypertrophy, and ubiquitinproteasome pathway [1]. Surprisingly, according to this 
Table 3 Genes and proteins with significant differentially alterations upon IA/IgG which leads to the prediction of an more active TGFßsignalling in non-responders (NR) than in responders (R) after therapy

\begin{tabular}{|c|c|c|c|c|c|}
\hline \multirow[t]{2}{*}{ Genes } & \multirow[t]{2}{*}{ Gene/protein name } & \multirow[t]{2}{*}{ Probe set ID } & \multicolumn{3}{|c|}{ Difference in IA/IgG effect NR vs R } \\
\hline & & & Uniprot ID & mRNA & Protein \\
\hline LOX & Lysyl oxidase & 215446_s_at & & 1.56 & n.d. \\
\hline CTGF & Connective tissue growth factor & 209101_at & & 1.54 & n.d. \\
\hline BGN & Biglycan & 213905_x_at & P21810 & 1.51 & 2.02 \\
\hline LTBP2 & Latent transforming growth factor beta binding protein 2 & 204682_at & & 1.49 & n.d. \\
\hline POSTN & Periostin & 210809_s_at & Q15063 & 1.49 & 2.12 \\
\hline COL3A1 & Collagen, type III, alpha 1 & 211161_s_at & & 1.43 & n.d. \\
\hline LOXL1 & Lysyl oxidase-like 1 & 203570_at & & 1.41 & n.d. \\
\hline COL1A2 & collagen, type I, alpha 2 & 202404_s_at & P08123 & 1.39 & 1.71 \\
\hline F2R & Coagulation factor II (thrombin) receptor & 203989_x_at & & 1.36 & n.d. \\
\hline INHBA & Inhibin, beta A & 227140_at & & 1.32 & n.d. \\
\hline NOX4 & NADPH oxidase 4 & 219773_at & & 1.31 & n.d. \\
\hline RASL11B & RAS-like, family 11 , member B & 219142_at & & 1.31 & n.d. \\
\hline COL1A1 & Collagen, type I, alpha 1 & 1556499_s_at & P02452 & 1.30 & 2.13 \\
\hline TAGLN & Transgelin & 205547_s_at & Q01995 & 1.30 & 1.29 \\
\hline SPP1 & Secreted phosphoprotein 1 & 209875_s_at & & 1.26 & n.d. \\
\hline VIM & Vimentin & 201426_s_at & P08670 & -1.10 & 1.43 \\
\hline NPPA & Natriuretic peptides A & 209957_s_at & P01160 & 1.37 & 1.36 \\
\hline MFAP4 & Microfibril-associated glycoprotein 4 & & P55083 & n.d. & 1.51 \\
\hline FN1 & Fibronectin & 211719_x_at & P02751 & 1.22 & 1.32 \\
\hline FBN1 & Fibrillin-1 & 202766_s_at & P35555 & 1.11 & n.d. \\
\hline FBLN5 & Fibulin-5 & & Q9UBX5 & n.d. & 1.85 \\
\hline
\end{tabular}

Bold: significant in proteome and transcriptome approach, italics: not significant

$N R$ non-responder, $R$ responder, $n . d$. not detected

study, none of these pathways was affected by IA/IgG, neither in responders nor in non-responders (see Online Resource Supplemental Material ESM 15, ESM 5 Supplemental Fig. S5). Only a few genes described as altered in DCM previously [1] were inversely affected in expression after IA/IgG in responders (seven genes: LTBP2, RGS4, SERPINE2, SH3GL2, TAGLN, FAM124A, MRO) and non-responders (six genes: ACTG2, MRO, IDS, MTHFD2L, CREB5, GLG1), respectively (see Online Resource Supplemental ESM 15 and Supplemental Tables ESM 2 and ESM 3). Similar observations were made on the proteome level: IA/IgG-related alterations overlapped only to a minor extent with the DCM-associated changes in protein levels reported previously [24] (see Online Resource Supplemental Tables ESM 9 and ESM 10). Hence, the molecular processes influenced by DCM and $\mathrm{IA} / \mathrm{IgG}$ seem to differ substantially.

In general, the magnitude of IA/IgG-associated alterations in mRNA levels of responders (244 genes) was similar to that of disease-associated alterations previously recorded (208 genes [1]. However, since the disease- and therapy-associated alterations barely overlapped, the IA/ IgG-related changes might not be causative for the functional and clinical improvement, but might rather reflect secondary effects. These findings are in line with observations by Margulies et al. who studied the molecular changes in human pre- and post-LVAD samples [39]. Only a minor proportion of HF-associated alterations exhibited normalisation indicating morphological and functional improvements without reversing pathological expression patterns [39]. Margulies et al. hypothesised that many HFassociated changes in transcript levels have only a limited role in regulation of cardiac structure and function and may represent epiphenomena [39]. In line with this observation, global heart failure-related gene expression patterns were largely unaffected by cardiac resynchronization therapy (CRT) [4]. However, dyssynchrony-induced expression changes were reversed in a region-specific manner for transcripts and proteins with metabolic and cell signalling function by CRT [4].

\section{Myocardial molecular changes in responders and non-responders upon IA/IgG therapy}

Improvement of heart function in the responder group after $\mathrm{IA} / \mathrm{IgG}$ was associated with a reduced LVIDD, a decrease 
in inflammation as determined by the number of infiltrating immune cells, and a decreased serum NT-pro BNP level. NT-pro BNP is stimulated by pathophysiological stressors, such as hypoxia, biomechanical stretch or ventricular hypertrophy [56], and is accepted as a biomarker reflecting the severity of HF [46]. The significant downregulation of NPPA and NPPB after IA/IgG that was found in responders exclusively might thus reflect differences in myocardial function of the patient subgroups. CORIN, the gene encoding atrial natriuretic peptide-converting enzyme, which catalyses the conversion of NT-pro ANP and to a lesser extent also NT-pro BNP [14], was found at significant higher levels after IA/IgG in responders compared with BL. Furthermore, CORIN was expressed at higher levels after $\mathrm{IA} / \mathrm{IgG}$ in responders compared with non-responders which might explain in part the reduced NT-pro BNP levels in this patient subgroup. In a murine DCM model, overexpression of CORIN was associated with improved cardiac function, reduced myocardial fibrosis, and prolonged survival [20]. These observed beneficial effects of increased corin levels might be secondary to the effects of processed natriuretic peptides ANP and BNP. Besides regulation of intravascular blood volume and vascular tone, BNP and ANP also display cardioprotective effects by inhibition of inflammation and cardiac fibrosis, and thus, each of these mechanisms may also influence the progression of dilated cardiomyopathy $[43,55]$. Especially, BNP is assumed to act locally as an anti-fibrotic factor by inhibiting collagen synthesis and proliferation of cardiac fibroblasts which, in turn, inhibits cardiac fibrosis [20, 43, 44].

In our study, major alterations were found for extracellular matrix components which were predominantly pronounced in responders and fit well with the observation of a decreased left ventricular diameter indicating myocardial recovery. After IA/IgG, responders showed lower expression of different collagens (Fig. 6) compared with non-responders. Furthermore, in non-responders, lumican levels increased but not in responders (Fig. 7). Increased expression of lumican in the myocardium of patients with HF was recently reported, and a pathophysiological role affecting extracellular matrix (ECM) was suggested by initiating increased ECM collagen crosslinking and cardiac fibrosis [15]. Furthermore, lower expression in responders than in non-responders after IA/ IgG was found for the heart failure marker and ECM component periostin which is associated with myocardial fibrosis in human failing hearts [57]. Animal experiments already revealed that inhibition of periostin gene expression resulted in a significant increase in survival rate accompanied by an improvement of LV function [30]. In addition, responders showed a downregulation of the fibrosis-associated gene CTGF [35], which is induced by growth factor TGF- $\beta$ [10]. Expression of TGF- $\beta$-dependent genes and levels of proteins, such as fibronectin (FN1) and different collagens (COL1A1 and COL1A2) [10], were significantly different (Table 3 ) in responders and non-responders after IA/IgG. Although no direct association of IA/IgG with TGF- 3 mRNA and protein levels was detected, a higher TGF- $B$ activity in non-responders was predicted independently for proteome as well as transcriptome data. The difference in the molecular remodelling might be caused by a higher expression of latent transforming growth factor binding protein 2 (LTBP2) in non-responders, which was recently described as a new biomarker for heart failure [3]. LTBP2 is part of the latent TGF-B1 complex. As a further component of the extracellular matrix, LTBP2 seems to contribute directly to myocardial remodelling and fibrosis, which was more pronounced in non-responders than in responders 6 months after IA/IgG. Improved LV function after LVAD implant therapy was also associated with reduced transcript levels of pro-fibrotic genes COL1A1 and COL3A1 as well as fibronectin 1 [18]. For extracellular matrix components, similar results were obtained in an LVAD implant study with patients suffering from cardiomyopathy. However, despite reduced levels of mRNA for TGF-31, CTGF, COL1A1, and COL3A1, only a modest reduction in tissue fibrosis was monitored between pre- and post-LVAD tissue samples by mechanical unloading [33]. Intriguingly, continuous-flow LVAD support is associated with increased myocardial fibrosis as well as circulating pro-fibrotic markers [36] and might emphasise the need of an earlier LVAD implantation for improvement in advanced HF. As a result of CRT-a therapeutic intervention against the loss of ventricular heart function in DCM patients-upregulation of contractility regulating genes, such as sarcoplasmatic reticulum calcium ATPase 2 $\alpha$ (ATP2A2), phospholamban (PLN), beta-1adrenoreceptor (ADRB1), and apelin (APL), was reported [26, 42, 53]. However, these genes were not found to be changed after IA/IgG irrespective of the responder status in our study (see Online Resource ESM 5 Supplemental Fig. S6). Our transcriptome and proteome data indicate differences in ECM remodelling instead of increase in expression or level of contractile proteins after IA/IgG.

\section{Study limitation}

A control group of DCM patients which did not receive IA/ IgG but for which FU biopsy was performed after 6 months was not available. Therefore, at least in theory, the changes in myocardial gene expression and proteome observed in responders may reflect differences in the natural course of disease rather than the effect of therapeutic intervention with IA/IgG. In this context, responders and non- 
responders display differences in disease duration. Therefore, it may be argued that differences in gene regulation after $\mathrm{IA} / \mathrm{IgG}$ found in responders and non-responders are related, at least in part, to the significant differences in disease duration with better myocardial recovery in patients exhibiting shorter disease duration. Compared with non-responders, the less advanced disease process in responders is also mirrored by significantly lower LVIDD at baseline. However, we consider it unlikely that the molecular differences observed are primarily attributable to differences in disease stages, because the same molecular differences between responders and non-responders are also seen in patients of both subgroups having similar disease duration (see Online Resource ESM 5 Supplemental Fig. S7). The total number of subjects available for the study as well as for the validation of results by qRTPCR approach limits the power of the analyses. However, the study is based on paired comparisons of samples of the same patients, which greatly reduces the overall variability. The gene expression and protein analyses data overlap only to minor extent (see Online Resource ESM 5 Supplemental Fig. S8), but the results point to a common result-a difference in the myocardial remodelling and fibrosis. One reason is the lower coverage of the proteome by the LCMS/MS analysis in comparison with the transcriptome accessible by microarray analyses. Furthermore, it is known that mRNA and protein levels do not essentially correlate, because the latter one depends, e.g. on mRNA stability, translation rate, protein degradation rate, and other factors.

\section{Conclusion}

This is the first study relating $\mathrm{IA} / \mathrm{IgG}$ therapy characteristics with comprehensive global molecular changes in myocardial biopsies of DCM patients. Improvement of LVEF, LVIDD, and NYHA classes, and inflammation status were accompanied by reduced serum natriuretic peptide levels and lower expression of TGF- $\beta$ dependent extracellular matrix components and fibrosis markers in responders. A few single molecules clearly show different expression pattern/protein levels in the patient subgroups, e.g. LTPB2, CORIN, periostin, and transgelin, but the importance or even causative role of those molecules in the functional recovery process in responders has to be shown in the future studies. IA/IgG did not normalise DCM-associated expression profiles reported earlier [1, 24]. In contrast to other studies on therapeutic intervention effects in DCM patients [26, 42, 53], normalised neurohormonal activity and beneficial LV remodelling in the responder group were not accompanied by a positive effect on molecules of the $\mathrm{Ca} 2^{+}$-handling. A placebo-controlled multicentre study on $\mathrm{IA} / \mathrm{IgG}$ therapy is still in progress (NCT00558584). Analysis of this data will show if IA/IgG is a potential treatment option for a subset of patients suffering from dilated cardiomyopathy, and material of this patient cohort might be useful to verify the findings of this pilot study.

Acknowledgments This work was supported by grant SFB/TR 19 of the German Research Foundation (DFG), by the DZHK (German Centre for Cardiovascular Research) and by the BMBF (German Ministry of Education and Research).

\section{Compliance with ethical standards}

Ethical statement Written informed consent was obtained by each patient and the protocol was approved by the Ethics Committee of the University of Greifswald, Germany (Reg.-Nr.: III UV 34/04). The investigation conforms to the principles of the Declaration of Helsinki.

Conflict of interest S.B.F. received research support and speaker fees from Fresenius Medical Care. All other authors declare they have no competing interests, or other interests that might be perceived to influence the results and discussion reported in this paper.

\section{References}

1. Ameling S, Herda LR, Hammer E, Steil L, Teumer A, Trimpert C, Dorr M, Kroemer HK, Klingel K, Kandolf R, Volker U, Felix SB (2013) Myocardial gene expression profiles and cardiodepressant autoantibodies predict response of patients with dilated cardiomyopathy to immunoadsorption therapy. Eur Heart $\mathrm{J}$ 34:666-675. doi:10.1093/eurheartj/ehs330

2. Aretz HT (1987) Myocarditis: the Dallas criteria. Hum Pathol 18:619-624. doi:10.1016/S0046-8177(87)80363-5

3. Bai Y, Zhang P, Zhang X, Huang J, Hu S, Wei Y (2012) LTBP-2 acts as a novel marker in human heart failure-a preliminary study. Biomarkers 17:407-415. doi:10.3109/1354750X.2012. 677860

4. Barth AS, Chakir K, Kass DA, Tomaselli GF (2012) Transcriptome, proteome, and metabolome in dyssynchronous heart failure and CRT. J Cardiovasc Transl Res 5:180-187. doi:10.1007/ s12265-011-9339-2

5. Breitling R, Armengaud P, Amtmann A, Herzyk P (2004) Rank products: a simple, yet powerful, new method to detect differentially regulated genes in replicated microarray experiments. FEBS Lett 573:83-92. doi:10.1016/j.febslet.2004.07.055

6. Bulut D, Creutzenberg G, Mugge A (2013) The number of regulatory $\mathrm{T}$ cells correlates with hemodynamic improvement in patients with inflammatory dilated cardiomyopathy after immunoadsorption therapy. Scand J Immunol 77:54-61. doi:10. 1111/sji. 12000

7. Bulut D, Scheeler M, Niedballa LM, Miebach T, Mugge A (2011) Effects of immunoadsorption on endothelial function, circulating endothelial progenitor cells and circulating microparticles in patients with inflammatory dilated cardiomyopathy. Clin Res Cardiol 100:603-610. doi:10.1007/s00392-011-0287-2

8. Caforio AL, Mahon NG, Baig MK, Tona F, Murphy RT, Elliott PM, McKenna WJ (2007) Prospective familial assessment in dilated cardiomyopathy: cardiac autoantibodies predict disease development in asymptomatic relatives. Circulation 115:76-83. doi:10.1161/CIRCULATIONAHA.106.641472 
9. Caforio AL, Pankuweit S, Arbustini E, Basso C, Gimeno-Blanes J, Felix SB, Fu M, Helio T, Heymans S, Jahns R, Klingel K, Linhart A, Maisch B, McKenna W, Mogensen J, Pinto YM, Ristic A, Schultheiss HP, Seggewiss H, Tavazzi L, Thiene G, Yilmaz A, Charron P, Elliott PM (2013) Current state of knowledge on aetiology, diagnosis, management, and therapy of myocarditis: a position statement of the European Society of Cardiology Working Group on Myocardial and Pericardial Diseases. Eur Heart J 34:2636-2648. doi:10.1093/eurheartj/eht210

10. Chen MM, Lam A, Abraham JA, Schreiner GF, Joly AH (2000) CTGF expression is induced by TGF-beta in cardiac fibroblasts and cardiac myocytes: a potential role in heart fibrosis. J Mol Cell Cardiol 32:1805-1819. doi:10.1006/jmcc.2000.1215

11. Cihakova D, Rose NR (2008) Pathogenesis of myocarditis and dilated cardiomyopathy. Adv Immunol 99:95-114. doi:10.1016/ S0065-2776(08)00604-4

12. Cooper LT, Baughman KL, Feldman AM, Frustaci A, Jessup M, Kuhl U, Levine GN, Narula J, Starling RC, Towbin J, Virmani R (2007) The role of endomyocardial biopsy in the management of cardiovascular disease: a scientific statement from the American Heart Association, the American College of Cardiology, and the European Society of Cardiology. Circulation 116:2216-2233. doi:10.1161/CIRCULATIONAHA.107.186093

13. Dickstein K, Cohen-Solal A, Filippatos G, McMurray JJ, Ponikowski P, Poole-Wilson PA, Stromberg A, van Veldhuisen DJ, Atar D, Hoes AW, Keren A, Mebazaa A, Nieminen M, Priori SG, Swedberg K (2008) ESC guidelines for the diagnosis and treatment of acute and chronic heart failure 2008: the Task Force for the diagnosis and treatment of acute and chronic heart failure 2008 of the European Society of Cardiology. Developed in collaboration with the Heart Failure Association of the ESC (HFA) and endorsed by the European Society of Intensive Care Medicine (ESICM). Eur J Heart Fail 10:933-989. doi:10.1016/j. ejheart.2008.08.005

14. Dong N, Chen S, Wang W, Zhou Y, Wu Q (2012) Corin in clinical laboratory diagnostics. Clin Chim Acta 413:378-383. doi:10.1016/j.cca.2011.10.032

15. Engebretsen KV, Lunde IG, Strand ME, Waehre A, Sjaastad I, Marstein HS, Skrbic B, Dahl CP, Askevold ET, Christensen G, Bjornstad JL, Tonnessen T (2013) Lumican is increased in experimental and clinical heart failure, and its production by cardiac fibroblasts is induced by mechanical and proinflammatory stimuli. FEBS J 280:2382-2398. doi:10.1111/febs.12235

16. Felix SB, Staudt A, Dorffel WV, Stangl V, Merkel K, Pohl M, Docke WD, Morgera S, Neumayer HH, Wernecke KD, Wallukat G, Stangl K, Baumann G (2000) Hemodynamic effects of immunoadsorption and subsequent immunoglobulin substitution in dilated cardiomyopathy: three-month results from a randomized study. J Am Coll Cardiol 35:1590-1598. doi:10.1016/S07351097(00)00568-4

17. Felix SB, Staudt A, Landsberger M, Grosse Y, Stangl V, Spielhagen $T$, Wallukat $\mathrm{G}$, Wernecke KD, Baumann G, Stangl K (2002) Removal of cardiodepressant antibodies in dilated cardiomyopathy by immunoadsorption. J Am Coll Cardiol 39:646-652. doi:10.1016/S0735-1097(01)01794-6

18. Felkin LE, Lara-Pezzi E, George R, Yacoub MH, Birks EJ, Barton PJR (2009) Expression of extracellular matrix genes during myocardial recovery from heart failure after left ventricular assist device support. J Heart Lung Transpl 28:117-122. doi:10.1016/j.healun.2008.11.910

19. Felkin LE, Lara-Pezzi EA, Hall JL, Birks EJ, Barton PJ (2011) Reverse remodelling and recovery from heart failure are associated with complex patterns of gene expression. J Cardiovasc Transl Res 4:321-331. doi:10.1007/s12265-011-9267-1

20. Gladysheva IP, Wang D, McNamee RA, Houng AK, Mohamad AA, Fan TM, Reed GL (2013) Corin overexpression improves cardiac function, heart failure, and survival in mice with dilated cardiomyopathy. Hypertension 61:327-332. doi:10.1161/ HYPERTENSIONAHA.112.193631

21. Goser S, Andrassy M, Buss SJ, Leuschner F, Volz CH, Ottl R, Zittrich S, Blaudeck N, Hardt SE, Pfitzer G, Rose NR, Katus HA, Kaya Z (2006) Cardiac troponin I but not cardiac troponin $\mathrm{T}$ induces severe autoimmune inflammation in the myocardium. Circulation 114:1693-1702. doi:10.1161/CIRCULATIONAHA. 106.635664

22. Haghikia A, Kaya Z, Schwab J, Westenfeld R, Ehlermann P, Bachelier K, Oettl R, von Kaisenberg CS, Katus HA, Bauersachs J, Hilfiker-Kleiner D (2015) Evidence of autoantibodies against cardiac troponin I and sarcomeric myosin in peripartum cardiomyopathy. Basic Res Cardiol 110:60. doi:10.1007/s00395015-0517-2

23. Hall JL, Fermin DR, Birks EJ, Barton PJ, Slaughter M, Eckman P, Baba HA, Wohlschlaeger J, Miller LW (2011) Clinical, molecular, and genomic changes in response to a left ventricular assist device. J Am Coll Cardiol 57:641-652. doi:10.1016/j.jacc. 2010.11.010

24. Hammer E, Goritzka M, Ameling S, Darm K, Steil L, Klingel K, Trimpert C, Herda LR, Dorr M, Kroemer HK, Kandolf R, Staudt A, Felix SB, Volker U (2011) Characterization of the human myocardial proteome in inflammatory dilated cardiomyopathy by label-free quantitative shotgun proteomics of heart biopsies. J Proteome Res 10:2161-2171. doi:10.1021/pr1008042

25. Heymans S, Hirsch E, Anker SD, Aukrust P, Balligand JL, CohenTervaert JW, Drexler H, Filippatos G, Felix SB, Gullestad L, Hilfiker-Kleiner D, Janssens S, Latini R, Neubauer G, Paulus WJ, Pieske B, Ponikowski P, Schroen B, Schultheiss HP, Tschope C, Van Bilsen M, Zannad F, McMurray J, Shah AM (2009) Inflammation as a therapeutic target in heart failure? A scientific statement from the Translational Research Committee of the Heart Failure Association of the European Society of Cardiology. Eur J Heart Fail 11:119-129. doi:10.1093/eurjhf/hfn043

26. Iyengar S, Haas G, Lamba S, Orsinelli DA, Babu GJ, Ferketich AK, Yamokoski L, Periasamy M, Abraham WT (2007) Effect of cardiac resynchronization therapy on myocardial gene expression in patients with nonischemic dilated cardiomyopathy. J Card Fail 13:304-311. doi:10.1016/j.cardfail.2007.01.005

27. Jahns R, Boivin V, Hein L, Triebel S, Angermann CE, Ertl G, Lohse MJ (2004) Direct evidence for a beta 1-adrenergic receptor-directed autoimmune attack as a cause of idiopathic dilated cardiomyopathy. J Clin Invest 113:1419-1429. doi:10.1172/ JCI200420149

28. Jahns R, Vr Boivin, Schwarzbach V, Ertl G, Lohse MJ (2008) Pathological autoantibodies in cardiomyopathy. Autoimmunity 41:454-461. doi:10.1080/08916930802031603

29. Kallwellis-Opara A, Dorner A, Poller WC, Noutsias M, Kuhl U, Schultheiss HP, Pauschinger M (2007) Autoimmunological features in inflammatory cardiomyopathy. Clin Res Cardiol 96:469-480. doi:10.1007/s00392-007-0524-x

30. Katsuragi N, Morishita R, Nakamura N, Ochiai T, Taniyama Y, Hasegawa Y, Kawashima K, Kaneda Y, Ogihara T, Sugimura K (2004) Periostin as a novel factor responsible for ventricular dilation. Circulation 110:1806-1813. doi:10.1161/01.CIR. 0000142607.33398.54

31. Kindermann I, Kindermann M, Kandolf R, Klingel K, Bultmann B, Muller T, Lindinger A, Bohm M (2008) Predictors of outcome in patients with suspected myocarditis. Circulation 118:639-648. doi:10.1161/CIRCULATIONAHA.108.769489

32. Knebel F, Bohm M, Staudt A, Borges AC, Tepper M, Jochmann N, Wernicke KD, Felix S, Baumann G (2004) Reduction of morbidity by immunoadsorption therapy in patients with dilated cardiomyopathy. Int J Cardiol 97:517-520. doi:10.1016/j.ijcard. 2003.12.003 
33. Koshman YE, Patel N, Chu M, Iyengar R, Kim T, Ersahin C, Lewis W, Heroux A, Samarel AM (2013) Regulation of connective tissue growth factor gene expression and fibrosis in human heart failure. J Card Fail 19:283-294. doi:10.1016/j.card fail.2013.01.013

34. Kühl U, Schultheiss HP (2009) Viral myocarditis: diagnosis, aetiology and management. Drugs 69:1287-1302. doi:10.2165/ 00003495-200969100-00001

35. Lang C, Sauter M, Szalay G, Racchi G, Grassi G, Rainaldi G, Mercatanti A, Lang F, Kandolf R, Klingel K (2008) Connective tissue growth factor: a crucial cytokine-mediating cardiac fibrosis in ongoing enterovirus myocarditis. J Mol Med 86:49-60. doi:10. 1007/s00109-007-0249-3

36. Lok SI, Nous FM, van Kuik J, van der Weide P, Winkens B, Kemperman H, Huisman A, Lahpor JR, de Weger RA, de Jonge $\mathrm{N}$ (2015) Myocardial fibrosis and pro-fibrotic markers in endstage heart failure patients during continuous-flow left ventricular assist device support. Eur J Cardiothorac Surg 48:407-415. doi:10.1093/ejcts/ezu539

37. Lowes B, Gilbert E, Abraham W, Minobe W, Larrabee P, Ferguson D, Wolfel E, Lindenfeld J, Tsvetkova T, Robertson A, Quaife R, Bristow M (2002) Myocardial gene expression in dilated cardiomyopathy treated with beat-blocking agents. N Engl J Med 346:1357-1365. doi:10.1056/NEJMoa012630

38. Mahrholdt H, Wagner A, Deluigi CC, Kispert E, Hager S, Meinhardt G, Vogelsberg H, Fritz P, Dippon J, Bock CT, Klingel K, Kandolf R, Sechtem U (2006) Presentation, patterns of myocardial damage, and clinical course of viral myocarditis. Circulation 114:1581-1590. doi:10.1161/CIRCULATIONAHA. 105.606509

39. Margulies KB, Matiwala S, Cornejo C, Olsen H, Craven WA, Bednarik D (2005) Mixed messages-transcription patterns in failing and recovering human myocardium. Circ Res 96:592-599. doi:10.1161/01.RES.0000159390.03503.e3

40. Maron BJ, Towbin JA, Thiene G, Antzelevitch C, Corrado D, Arnett D, Moss AJ, Seidman CE, Young JB (2006) Contemporary definitions and classification of the cardiomyopathies: an American Heart Association Scientific Statement from the Council on Clinical Cardiology, Heart Failure and Transplantation Committee; Quality of Care and Outcomes Research and Functional Genomics and Translational Biology Interdisciplinary Working Groups; and Council on Epidemiology and Prevention. Circulation 113:1807-1816. doi:10.1161/CIRCULATIONAHA. 106.174287

41. Mueller KA, Mueller II, Eppler D, Zuern CS, Seizer P, Kramer U, Koetter I, Roecken M, Kandolf R, Gawaz M, Geisler T, Henes JC, Klingel K (2015) Clinical and histopathological features of patients with systemic sclerosis undergoing endomyocardial biopsy. PLoS One 10:e0126707. doi:10.1371/journal.pone. 0126707

42. Mullens W, Bartunek J, Wilson Tang WH, Delrue L, Herbots L, Willems R, De Bruyne B, Goethals M, Verstreken S, Vanderheyden M (2008) Early and late effects of cardiac resynchronization therapy on force-frequency relation and contractility regulating gene expression in heart failure patients. Heart Rhythm 5:52-59. doi:10.1016/j.hrthm.2007.09.009

43. Nishikimi T, Maeda N, Matsuoka H (2006) The role of natriuretic peptides in cardioprotection. Cardiovasc Res 69:318-328. doi:10. 1016/j.cardiores.2005.10.001

44. Ogawa Y, Tamura N, Chusho H, Nakao K (2001) Brain natriuretic peptide appears to act locally as an antifibrotic factor in the heart. Can J Physiol Pharmacol 79:723-729. doi:10.1139/y01052

45. Okazaki T, Tanaka Y, Nishio R, Mitsuiye T, Mizoguchi A, Wang J, Ishida M, Hiai H, Matsumori A, Minato N, Honjo T (2003)
Autoantibodies against cardiac troponin I are responsible for dilated cardiomyopathy in PD-1-deficient mice. Nat Med 9:1477-1483. doi:10.1038/nm955

46. Panagopoulou V, Deftereos S, Kossyvakis C, Raisakis K, Giannopoulos G, Bouras G, Pyrgakis V, Cleman MW (2013) NTproBNP: an important biomarker in cardiac diseases. Curr Top Med Chem 13:82-94. doi:10.2174/1568026611313020002

47. Remme WJ, Swedberg K (2001) Guidelines for the diagnosis and treatment of chronic heart failure. Eur Heart J 22:1527-1560. doi:10.1053/euhj.2001.2783

48. Staudt A, Herda LR, Trimpert C, Lubenow L, Landsberger M, Dorr M, Hummel A, Eckerle LG, Beug D, Muller C, Hoffmann W, Weitmann K, Klingel K, Kandolf R, Kroemer HK, Greinacher A, Felix SB (2010) Fcgamma-receptor IIa polymorphism and the role of immunoadsorption in cardiac dysfunction in patients with dilated cardiomyopathy. Clin Pharmacol Ther 87:452-458. doi:10.1038/clpt.2009.246

49. Staudt A, Hummel A, Ruppert J, Dorr M, Trimpert C, Birkenmeier K, Krieg T, Staudt Y, Felix SB (2006) Immunoadsorption in dilated cardiomyopathy: 6-month results from a randomized study. Am Heart J 152:712-716. doi:10.1016/j.ahj.2006.06.027

50. Staudt A, Schaper F, Stangl V, Plagemann A, Bohm M, Merkel K, Wallukat G, Wernecke KD, Stangl K, Baumann G, Felix SB (2001) Immunohistological changes in dilated cardiomyopathy induced by immunoadsorption therapy and subsequent immunoglobulin substitution. Circulation 103:2681-2686. doi:10.1161/01.CIR.103.22.2681

51. Storey J (2002) A direct approach to false discovery rates. J R Stat Soc B 64:479-498. doi:10.1111/1467-9868.00346

52. Swedberg K, Cleland J, Dargie H, Drexler H, Follath F, Komajda M, Tavazzi L, Smiseth OA, Gavazzi A, Haverich A, Hoes A, Jaarsma T, Korewicki J, Levy S, Linde C, Lopez-Sendon JL, Nieminen MS, Pierard L, Remme WJ (2005) Guidelines for the diagnosis and treatment of chronic heart failure: executive summary (update 2005): the Task Force for the Diagnosis and Treatment of Chronic Heart Failure of the European Society of Cardiology. Eur Heart J 26:1115-1140. doi:10.1093/eurheartj/ ehi204

53. Vanderheyden M, Mullens W, Delrue L, Goethals M, de Bruyne B, Wijns W, Geelen P, Verstreken S, Wellens F, Bartunek J (2008) Myocardial gene expression in heart failure patients treated with cardiac resynchronization therapy responders versus nonresponders. J Am Coll Cardiol 51:129-136. doi:10.1016/j. jacc.2007.07.087

54. Vanderheyden M, Mullens W, Delrue L, Goethals M, Verstreken S, Wijns W, de Bruyne B, Bartunek J (2008) Endomyocardial upregulation of beta1 adrenoreceptor gene expression and myocardial contractile reserve following cardiac resynchronization therapy. J Card Fail 14:172-178. doi:10.1016/j.cardfail.2007. 10.016

55. Vollmar AM (2005) The role of atrial natriuretic peptide in the immune system. Peptides 26:1086-1094. doi:10.1016/j.peptides. 2004.08.034

56. Xu-Cai YO, Wu Q (2010) Molecular forms of natriuretic peptides in heart failure and their implications. Heart 96:419-424. doi:10. 1136/hrt.2008.164145

57. Zhao S, Wu H, Xia W, Chen X, Zhu S, Zhang S, Shao Y, Ma W, Yang D, Zhang J (2014) Periostin expression is upregulated and associated with myocardial fibrosis in human failing hearts. J Cardiol 63:373-378. doi:10.1016/j.jjcc.2013.09.013

58. Zuern CS, Walker B, Sauter M, Schaub M, Chatterjee M, Mueller K, Rath D, Vogel S, Tegtmeyer R, Seizer P, Geisler T, Kandolf R, Lang F, Klingel K, Gawaz M, Borst O (2015) Endomyocardial expression of SDF-1 predicts mortality in patients with suspected myocarditis. Clin Res Cardiol. doi:10.1007/s00392-015-0871-y 